\title{
Analisis Kinerja Traksi Dan Redesign Transmisi Armored Personnel Carrier Komodo 4x4
}

\author{
M. Anggi Siregar dan I Nyoman Sutantra \\ Departemen Teknik Mesin, Fakultas Teknologi Industri, Institut Teknologi Sepuluh Nopember (ITS) \\ e-mail: tantra@me.its.ac.id
}

\begin{abstract}
Abstrak-Dunia militer belakangan ini mengalami perkembangan yang cukup pesat. Salah satu perkembangan teknologi transportasi bidang militer adalah mobil anti-peluru atau biasa disebut Armored Personnel Carrier (APC). Salah satu produk transportasi militer PT. Pindad adalah APC KOMODO 4X4 yang merupakan kendaraan tempur anti-peluru yang dilengkapi dengan persenjataan berat. APC KOMODO 4X4 berkapasitas 5 penumpang dan memiliki daya sebesar $158 \mathrm{~kW}$ namun hanya memiliki kecepatan maksimum sebesar $100 \mathrm{~km} / \mathrm{h}$ serta daya tanjak sebesar $60 \%$. Sedangkan kompetitornya, GKN Simba yang memiliki daya engine sebesar $160 \mathrm{~kW}$ dan berkapasitas 10 penumpang, memiliki kemampuan yang sama dengan beban yang dua kali lipat lebih besar. Oleh karena itu perlu dilakukan analisa kinerja APC KOMODO 4X4 agar dapat meningkatkan performa kendaraan tersebut. Dalam penelitian ini telah dilakukan tiga tahap analisa. Tahap pertama merupakan analisa perhitungan grafik karakteristik traksi kendaraan. Tahap kedua, dilakukan analisa terhadap karakteristik tenaga kendaraan. Selanjutnya tahap ketiga dilakukan evaluasi terhadap grafik karakteristik traksi standar kendaraan, kemudian meredesain rasio setiap tingkat tran s mi si menggunakan teori progresi geometri. Dari penelitian ini diperoleh grafik karakteristik traksi standar kendaraan serta hasil redesain 6,7 , dan 8 tingkat transmisi. Setelah dilakukan analisa ternyata kemampuan tanjak kendaraan tidak sesuai dengan klaim yang ada pada brosur kendaraan dimana brosur tersebut mengklaim kendaraan mampu menanjak dengan $60 \%$ gradeability sedangkan pada analisa perhitungan hanya $50 \%$. Setelah dilakukan redesign dengan 6 tingkat kecepatan, kendaraan mampu menanjak dengan gradeability $70 \%$ dan menempuh kecepatan maksimum sebesar 140 km/jam.
\end{abstract}

Kata Kunci-APC KOMODO 4X4, Karakteristik traksi, progresi geometri, redesign, rasio transmisi.

\section{PENDAHULUAN}

$\mathrm{P}$ ERKEMBANGAN industri di dunia militer saat ini sudah melaju dengan pesat. PT. Pindad (Persero) telah bekerja sama dengan berbagai pihak, baik dalam maupun luar negeri dalam upaya untuk mengembangkan teknologi fungsi kendaraan khusus, termasuk kendaraan anti-peluru atau yang biasa disebut Armored Personnel Carrier (APC). Salah satu produk Armored Personnel Carrier milik PT. Pindad adalah APC KOMODO 4X4 yang digunakan sebagai kendaraan pengintai maupun tugas berat yang lainnya terutama pada medan jalan yang ekstirm.

Kendaraan khusus APC KOMODO 4X4 dirancang dan di assembly oleh PT. Pindad di manufacturing facility Pindad, Bandung, Jawa Barat. Kendaraan ini memiliki transmisi manual dengan 6 tingkat gigi dan satu tingkat gigi mundur (reverse) yang membuatnya dapat menempuh jalan off-road. APC KOMODO 4X4 juga dilengkapi dengan Senapan Mesin Berat (SMB) kaliber $12.7 \mathrm{~mm}$ serta Remote Control Weapon System (RCWS). GKN Simba adalah produk Armored Personnel Carrier buatan Inggris yang digunakan oleh negara Filipina. GKN Simba tersebut memiliki output daya engine sebesar $160 \mathrm{~kW}$ dengan konfigurasi All-Wheel Drive 4X4. Kendaraan ini mampu mengangkut sampai dengan 10 orang dan mampu melaju dengan kecepatan maksimum $100 \mathrm{~km} / \mathrm{h}$ pada jalan beraspal. Berdasarakan data tersebut, APC KOMODO 4X4 yang hanya mampu mengangkut 5 personnel dengan output engine $158 \mathrm{~kW}$ hanya mampu mencapai kecepatan maksimum yang sama yaitu $100 \mathrm{~km} / \mathrm{h}$. Dari permasalahan tersebut perlu dilakukan analisis transmisi dan kinerja traksi pada APC KOMODO 4X4 untuk mengetahui gaya hambat yang terjadi serta gaya dorong yang dihasilkan oleh kendaraan tersebut. Selanjutnya perlu dilakukan redesign rasio transmisi kendaraan APC KOMODO 4X4 yang bertujuan untuk menyelesaikan permasalahan yang terdapat pada kendaraan tersebut, yaitu meningkatkan kecepatan maksimum, percepatan serta gradeability.

\section{METODE PENELITIAN}

Adapun metode penelitian yang dilakukan dapat dijelaskan sesuai dengan urutan analisa berikut:

\section{A. Menghitung Gaya Hambat Kendaraan}

Gaya-gaya yang bekerja pada sebuah kendaraan yang sedang melaju pada sebuah permukaan dengan sudut tanjak tertentu dapat dijabarkan dalam gambar 2 berikut,

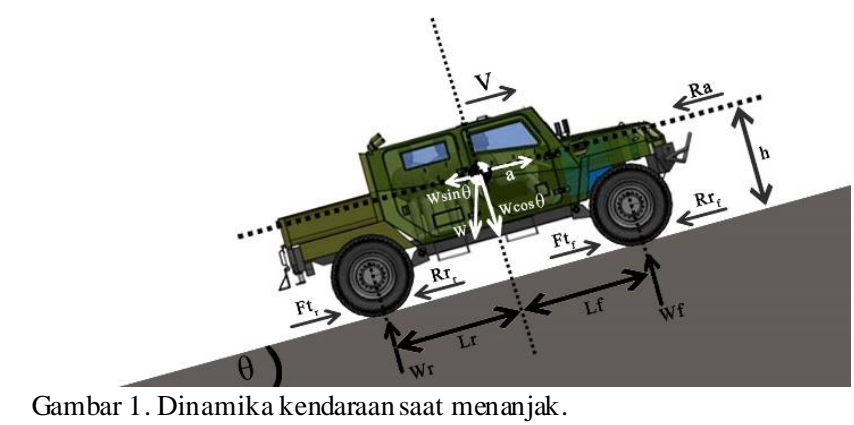

Gaya dorong $\left(\mathrm{F}_{\mathrm{t}}\right)$ dibagi menjadi dua, yaitu gaya dorong roda depan $\left(\mathrm{F}_{\mathrm{f}}\right)$ dan gaya dorong roda belakang $\left(\mathrm{F}_{\mathrm{r}}\right)$. Gaya dorong pada kendaraan yang sedang melaju dihambat oleh 3 
macam gaya hambat, yaitu aerodinamic resistance $\left(\mathrm{R}_{\mathrm{a}}\right)$, rolling resistance $\left(\mathrm{R}_{\mathrm{r}}\right)$, dan gaya hambat akibat sudut tanjak $\left(\mathrm{R}_{\mathrm{g}}\right)$.

Gaya hambat udara (drag force) dipengaruhi beberapa faktor antara lain hambatan bentuk, hambatan pusaran/turbulensi, hambatan tonjolan dan hambatan aliran dalam. Tetapi pada kenyataannya hanya hambatan bentuk dan hambatan pusaran saja yang paling besar pengaruhnya terhadap gaya hambat angin secara keseluruhan. Gaya hambat angin dapat dihitung dengan persamaan berikut:

$$
\mathrm{R}_{\mathrm{a}}=\frac{1}{2} \times \rho \times \mathrm{C}_{\mathrm{d}} \times \mathrm{A}_{\mathrm{f}} \times \mathrm{V}_{\mathrm{a}}^{2}
$$

dimana,

$\mathrm{R}_{\mathrm{a}} \quad$ Hambatan aerodinamika $(\mathrm{N})$

$\rho \quad=$ Massa jenis udara $\left(\mathrm{kg} \cdot \mathrm{m}^{3}\right)$

$\mathrm{C}_{\mathrm{d}} \quad=$ Koefisien drag

$\mathrm{A}_{\mathrm{f}}=$ Luas frontal kendaraan $\left(\mathrm{m}^{2}\right)$

$\mathrm{V}_{\mathrm{a}} \quad=$ Kecepatan relative angin terhadap kendaraan $(\mathrm{m} / \mathrm{s})$

Besar $\mathrm{C}_{\mathrm{d}}$ dari kendaraan APC KOMODO 4X4 adalah sebesar 0.57. Sedangkan luas frontal area dihitung menggunakan software CAD sebesar $4.22 \mathrm{~m}^{2}$.

Gaya hambat yang berikutnya adalah gaya hambat rolling yaitu gaya hambat yang disebabkan oleh sifat histeris is ban karena adanya defleksi dari ban. Defleksi tersebut menyebabkan terjadinya momen tahanan rolling yang dapat melawan atau menghambat gerakan ban. Untuk mencari besarnya gaya hambat rolling yang terjadi, sebelumnya harus ditentukan terlebih dahulu besarnya koefisien hambatan rolling $\left(\mathrm{f}_{\mathrm{r}}\right)$. Besarnya $\mathrm{f}_{\mathrm{r}}$ dapat dicari menggunakan persamaan hasil eksperimen J.J Taborek [1] berikut:

$$
\mathrm{f}_{\mathrm{r}}=\mathrm{f}_{\mathrm{o}}+\mathrm{f}_{\mathrm{s}}\left(\frac{V}{100}\right)^{2,5}
$$

dimana,

$$
\begin{aligned}
\mathrm{f}_{\mathrm{r}}= & \text { Koefisien hambatan rolling } \\
\mathrm{f}_{\mathrm{O}} \text { dan } \mathrm{f}_{\mathrm{s}}= & \text { Koefisien yang tergantung pada tekanan ban, didapat } \\
& \text { dari gambar } 3 \\
\mathrm{~V} \quad= & \text { Kecepatan kendaraan dalam } \mathrm{km} / \mathrm{jam}
\end{aligned}
$$

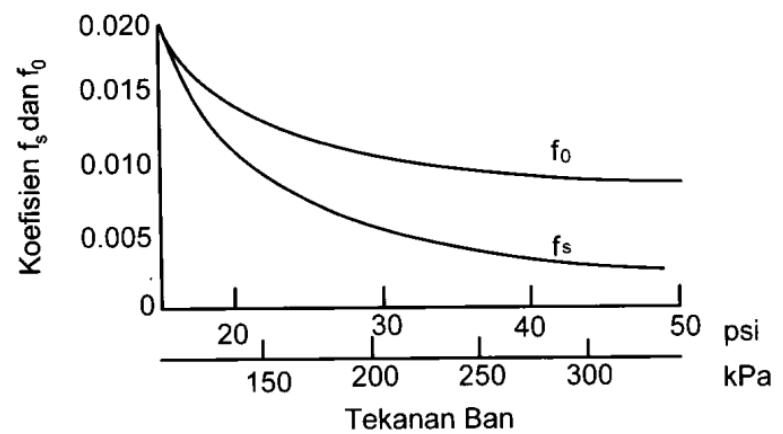

Gambar 2. Grafik pengaruh tekanan ban terhadap $\mathrm{f}_{\mathrm{o}}$ dan $\mathrm{f}_{\mathrm{s}}$.

Setelah mendapatkan nilai koefisien hambat rolling $\left(\mathrm{f}_{\mathrm{r}}\right)$, dengan menggunakan rumus di bawah ini maka didapat nilai dari gaya hambat rolling,

$$
\mathrm{R}_{\mathrm{r}}=\mathrm{f}_{\mathrm{r}} x \mathrm{~W} \cos \theta
$$

dimana,

$\mathrm{R}_{\mathrm{r}} \quad$ = Gaya hambatan rolling $(\mathrm{N})$

$\mathrm{f}_{\mathrm{r}} \quad=$ Koefisien hambatan rolling

$\mathrm{W}=$ Berat kendaraan $(\mathrm{N})$
Gaya hambat yang terakhir adalah gaya hambat tanjakan, gaya hambat yang terjadi dikarenakan adanya sudut tanjakan pada jalan. Dengan adanya gaya hambatan tanjakan maka beban kendaraan akan bertambah akibat pengaruh gaya gravitasi bumi. Besar gaya hambat akibat sudut tanjak dapat dihitung dengan rumus berikut:

$$
\mathrm{R}_{\mathrm{g}}=\mathrm{W} \sin \theta
$$

dimana,

$$
\begin{array}{ll}
\mathrm{R}_{\mathrm{g}} & =\text { Gaya hambat tanjakan }(\mathrm{N}) \\
\mathrm{W} & =\text { Berat kendaraan }(\mathrm{N}) \\
\theta & =\text { Sudut tanjakan dalam derajat }
\end{array}
$$

Setelah mengetahui penjelasan dari masing-masing gaya hambat yang mempengaruhi kendaraan, maka dapat dirumuskan gaya hambat total yang terjadi pada kendaraan sebagaiberikut:

$$
F_{r}=R_{a}+R_{r}+R_{g}
$$

\section{B. Menghitung Gaya Dorong Kendaraan}

Gaya dorong adalah gaya yang bekerja berlawanan dengan arah gerak gaya hambat kendaraan. Untuk dapat bergerak maju, suatu kendaraan harus memiliki gaya dorong yang cukup untuk melawan semua gaya hambat yang terjadi pada kendaraan. Untuk menghitung besarnya gaya dorong yang mampu dihasilkan kendaraan, digunakan persamaan [2] berikut:

$$
\mathrm{F}_{\mathrm{t}}=\frac{\operatorname{ig} x \text { it } x \mathrm{Me} x \eta \mathrm{t}}{R}
$$

dimana,

$\mathrm{F}_{\mathrm{t}} \quad=$ Gaya dorong pada kendaraan $(\mathrm{N})$

it $_{\text {ig }} \quad=$ Perbangindan gigi transmisi

$\mathrm{ig}_{\mathrm{g}} \quad$ Perbandingan transmisi pada gardan

$\eta_{\mathrm{t}} \quad=$ Efisiensi transmisi

$\mathrm{R}=$ Jari-jari roda $(\mathrm{m})$

\section{Desain Tingkatan Gigi}

Salah satu cara untuk mencari perbandingan gigi antara tingkat transmisi terendah dan tertinggi adalah dengan metode progresi geometri. Batas kecepatan operasi dari mesin terendah $\left(\right.$ ne $\left._{2}\right)$ dan tertinggi (ne 1 ) harus ditetapkan terlebih dahulu. Penetapan ini berdasarkan karakteristik torsi dari mesin, dimana batas ini umumnya dipilih pada sekitar torsi maksimum engine. Sebagai contoh, untuk transmisi 4 tingkat kecepatan, didapat hubungan perbandingan gigi sebagai berikut:

$$
\frac{i 2}{i 1}=\frac{i 3}{i 2}=\frac{i 4}{i 3}=\frac{n e 2}{n e 1}=\mathrm{K}_{\mathrm{g}}
$$

dimana,

$\mathrm{i}_{1} \mathrm{i}_{2} \mathrm{i}_{3} \mathrm{i}_{4}=$ Perbandingan gigi pada tingkat transmisi $1,2,3,4$

$\mathrm{K}_{\mathrm{g}} \quad=$ Konstanta perbandingan

Langkah pertama untuk merancang tingkat transmisi adalah menentukan terlebih dahulu rasio transmisi pertama dan rasio transmisi terakhir dari kendaraan. Untuk menentukan rasio transmisi pertama, dapat digunakan rumus berikut:

$$
\mathrm{i}_{1}=\frac{F 1 \times R}{\text { Me } \times i g \times \eta \mathrm{t}}
$$

Kemudian rasio transmisi pada tingat terakhir (n) dihitung menggunakan rumus: 


$$
\mathrm{i}_{\mathrm{n}}=\frac{F n \times R}{\operatorname{Me} \times i g \times \eta \mathrm{t}}
$$

Dengan demikian, nilai factor $\mathrm{K}_{\mathrm{g}}$ dapat ditentukan dengan menggunakan persamaan 2.24. Selanjutnya, nilai $\mathrm{K}_{\mathrm{g}}$ tersebut digunakan untuk menentukan nilai $i_{2}$, i3 dan seterusnya.

$$
\mathrm{K}_{\mathrm{g}}=\left(\frac{i n}{i 1}\right)^{\frac{1}{n-1}}
$$

\section{Karakteristik Transmisi Kendaraan}

Untuk dapat mengetahui karakteristik suatu kendaraan, lebih mudah jika digunakan grafik gaya dorong - kecepatan dari kendaraan tersebut. Pada grafik tersebut ditunjukkan hambatan rolling $\left(\mathrm{R}_{\mathrm{r}}\right)$ dan hambatan aerodinamik $\left(\mathrm{R}_{\mathrm{a}}\right)$ yang terjadi pada kendaraan, serta gaya dorong total, gaya dorong bersih, dan gaya dorong maksimum yang dapat terjadi pada bidang kontak ban dan jalan dengan asumsi koefisiesn gesek tertentu. Grafik tersebut juga menunjukkan gradeability kendaraan sehingga besarnya kecepatan maksimum yang dapat dicapai kendaraan pada gradeability tertentu dapat diketahui.

\section{E. Karakteristik Tenaga Kendaraan}

Tenaga yang dibutuhkan untuk menggerakkan kendaraan pada beban dan kecepatan tertentu dinamakan road load horsepower (Rhp) [3]. Besarnya tenaga yang dibutuhkan (Rhp) tergantung pada besarnya gaya hambat yang terjadi pada kendaraan $\left(\mathrm{F}_{\mathrm{r}}\right)$ dan kecepatan kendaraan $\left(\mathrm{V}_{\mathrm{k}}\right)$. Tenaga yang dibutuhkan dapat dirumuskan sebagai berikut:

$$
\mathrm{Rhp}=\frac{F r \times V k}{375}
$$

dimana,

Rhp = Road load horsepower $(\mathrm{hp})$

$\mathrm{F}_{\mathrm{r}} \quad$ = Gaya hambat kendaraan (lb)

$\mathrm{V}_{\mathrm{k}} \quad=$ Kecepatan kendaraan (mil/jam)

Untuk mendapatkan grafik karakteristik tenaga, dibutuhkan data input berupa tenaga yang disuplai dan kecepatan kendaraan. Tenaga yang disuplai dapat dihitung menggunakan perasamaan sebagai berikut:

dimana,

$$
\mathrm{P}=\mathrm{P}_{\mathrm{e}} x \eta_{\mathrm{e}}
$$

$\mathrm{P}=$ Tenaga aktual yang disuplai oleh engine

$\mathrm{P}_{\mathrm{e}}=$ Tenaga engine

$\eta_{\mathrm{e}}=$ Effisiensi engine

\section{HASIL DAN ANALISIS}

Berdasarkan data teknis dan spesifikasi kendaraan APC KOMODO 4X4, diperhitungkan dan dianalisa karakteristik traksi dan karakteristik tenaga kendaraan dengan memperhatikan beberapa batasan:

1. Analisa dilakukan dengan kondisi kendaraan terisi muatan seberat $350 \mathrm{~kg}$ (5 personnel) dan dilengkapi dengan senjata SMB (Senapan Mesin Berat) kaliber 12.7 $\mathrm{mm}$ seberat $30 \mathrm{~kg}$ sehingga berat kendaraan menjadi $7650 \mathrm{~kg}[4]$.

2. Kinerja engine tidak dipengaruhi oleh lingkungan sekitar.

3. Kendaraan menggunakan bahan bakar solar.

4. Jalan yang dilalui menanjak dan rata (tidak bergelombang).

5. Tekanan ban 50 psi.
6. Tipe ban yang digunakan adalah 365/80 R20 runflat tyre.

\section{A. Perhitungan Gaya Hambat Kendaraan}

Dengan menggunakan persamaan yang telah disebutkan sebelumnya, didapatkan grafik gaya hambat terhadap kecepatan kendaraan seperti berikut,

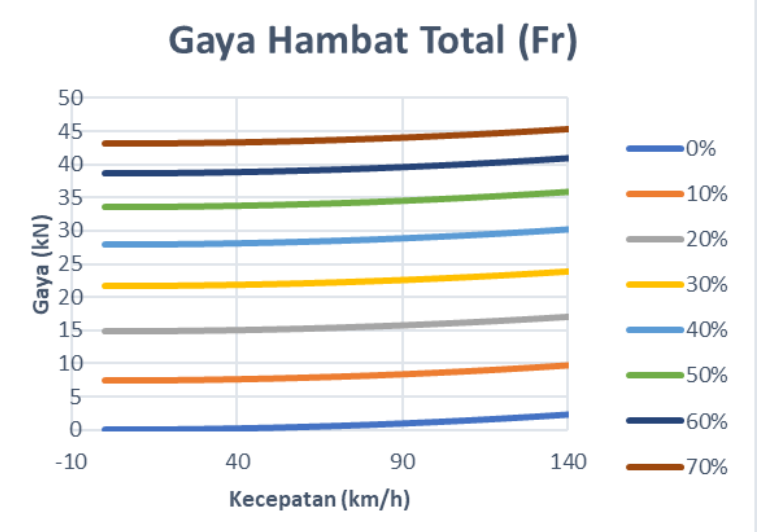

Gambar 3. Grafik gaya hambat total kendaraan.

\section{B. Perhitungan Gaya Dorong Kendaraan}

Gaya dorong kendaraan dapat diperhitungkan menggunakan persamaan (6). Berikut merupakan karakteristik traksi kendaraan kondisi standar yang diperoleh dari memplotting gaya dorong dan gaya hambat kendaraan terhadap kecepatan kendaraan:

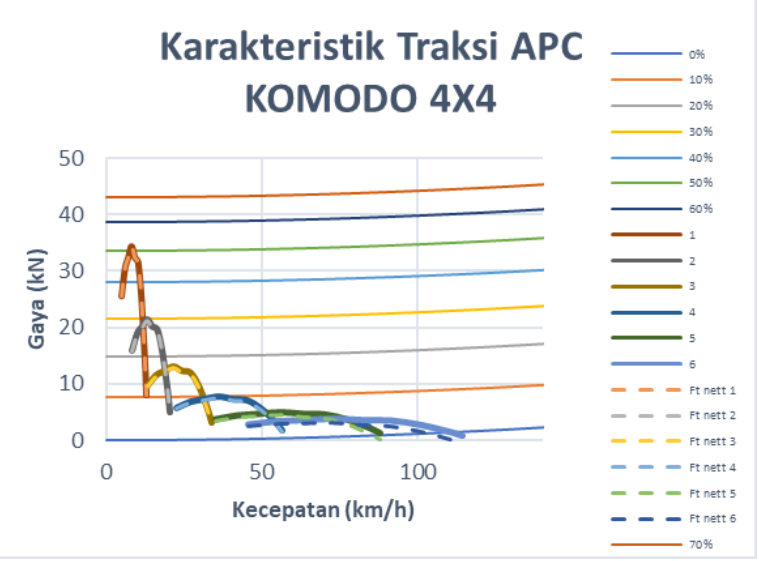

Gambar 4. Grafik karakteristik traksi kendaraan standar.

Garis tipis pada grafik tersebut mewakilkan gaya hambat yang terjadi pada kendaraan pada setiap tingkat gradeability. Sedangkan garis tebal merupakan gaya dorong yang mampu dihasilkan kendaraan pada setiap tingkat gigi. Dapat dilihat bahwa pada kondisi standar, kendaraan hanya mampu melalui jalan tanjak dengan gradeability sebesar 50\% (garis hijau) dan kecepatan maksimum sebesar $110 \mathrm{~km} / \mathrm{jam}$. Kedua hal terseebut dijadikan indikator perbaikan rasio gigi dan jumlah tingkat transmisi pada penelitian ini.

Grafik dibawah ini merupakan grafik karakteristik tenaga kendaraan pada kondisi transmisi standar yang diperoleh melalui perhitungan daya yang disuplai kendaraan pada setiap tingkat transmisi kemudian dibandingkan dengan daya yang dibutuhkan kendaraan pada tingkatan kecepatan tertentu (Rhp). 


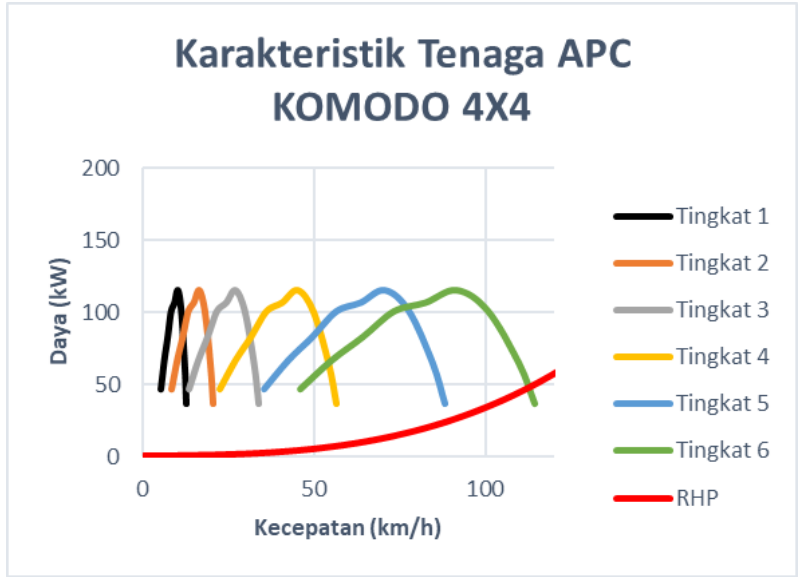

Gambar 5. Grafik karakteristik tenaga kendaraan standar.

\section{Perhitungan Redesign Rasio Transmisi}

Tingkat gigi pertama dirancang dengan mempertimbangkan gaya hambat gradeability yang ingin dicapai pada gigi awal tersebut. Dimana $F_{1}=R_{a}+R_{r}+R_{g}$ kemudian rasio awal diperhitungkan menggunakan persamaan (8):

$$
\begin{gathered}
\mathrm{i}_{1}=\frac{43876.409 \times 0.548}{600 \times 5.857 \times 0.78} \\
\mathrm{i}_{1}=8.711
\end{gathered}
$$

Kemudian rasio gigi terakhir ditentukan berdasarkan kecepatan maksimum yang diharapkan mampu dicapai oleh kendaraan, yaitu $160 \mathrm{~km} / \mathrm{jam}$. Saat berada pada tingkat gigi terakhir, beban yang dialami kendaraan terdiri dari gaya hambat angin serta gaya hambat rolling, sehingga besarnya gaya total adalah $F_{n}=R_{a}+R_{r}$

$$
\begin{gathered}
\mathrm{i}_{\mathrm{n}}=\frac{3001.66 \times 0.548}{600 \times 5.857 \times 0.78} \\
\mathrm{i}_{\mathrm{n}}=0.6
\end{gathered}
$$

Setelah il dan in didapatkan, rasio hail redesign untuk 6,7, dan 8 tingkat kecepatan dapat dihitung menggunakan persamaan (10) dengan hasil sebagai berikut:

1) Pemasangan 6 tingkat kecepatan

\section{Sehingga,}

$$
\begin{aligned}
\mathrm{Kg} & =\left(\frac{0.6}{8.711}\right)^{\frac{1}{5}} \\
\mathrm{Kg} & =0.585
\end{aligned}
$$

$\mathrm{i}_{2}=0.585 \times 8.711=5.095$

$\mathrm{i}_{3}=0.585 \times 5.095=2.981$

$\mathrm{i}_{4}=0.585 \times 2.981=1.743$

$\mathrm{i}_{5}=0.585 \times 1.743=1.020$

2) Pemasangan 7 tingkat kecepatan

Sehingga,

$$
\begin{aligned}
\mathrm{Kg} & =\left(\frac{0.6}{8.711}\right)^{\frac{1}{6}} \\
\mathrm{Kg} & =0.64
\end{aligned}
$$

$\mathrm{i}_{2}=0.64 \times 8.711=5.575$

$\mathrm{i}_{3}=0.64 \times 5.575=3.568$

$\mathrm{i}_{4}=0.64 \times 3.568=2.283$

$\mathrm{i}_{5}=0.64 \times 2.283=1.461$

$\mathrm{i}_{6}=0.64 \times 1.461=0.935$
3) Pemasangan 8 tingkat kecepatan

Sehingga,

$$
\begin{aligned}
& \mathrm{Kg}=\left(\frac{0.6}{8.711}\right)^{\frac{1}{7}} \\
& \mathrm{Kg}=0.682
\end{aligned}
$$

$$
\begin{aligned}
& \mathrm{i}_{2}=0.682 \times 8.711=5.940 \\
& \mathrm{i}_{3}=0.682 \times 5.095=4.051 \\
& \mathrm{i}_{4}=0.682 \times 2.981=2.763 \\
& \mathrm{i}_{5}=0.682 \times 1.743=1.884 \\
& \mathrm{i}_{6}=0.682 \times 1.743=1.285 \\
& \mathrm{i}_{7}=0.682 \times 1.743=0.876
\end{aligned}
$$

\section{Grafik Karakteristik Hasil Redesign}

Grafik karakteristik traksi hasil redesign dengan 6,7, dan 8 tingkat kecepatan ditampilkan pada gambar 7,8, dan 9 secara urut.

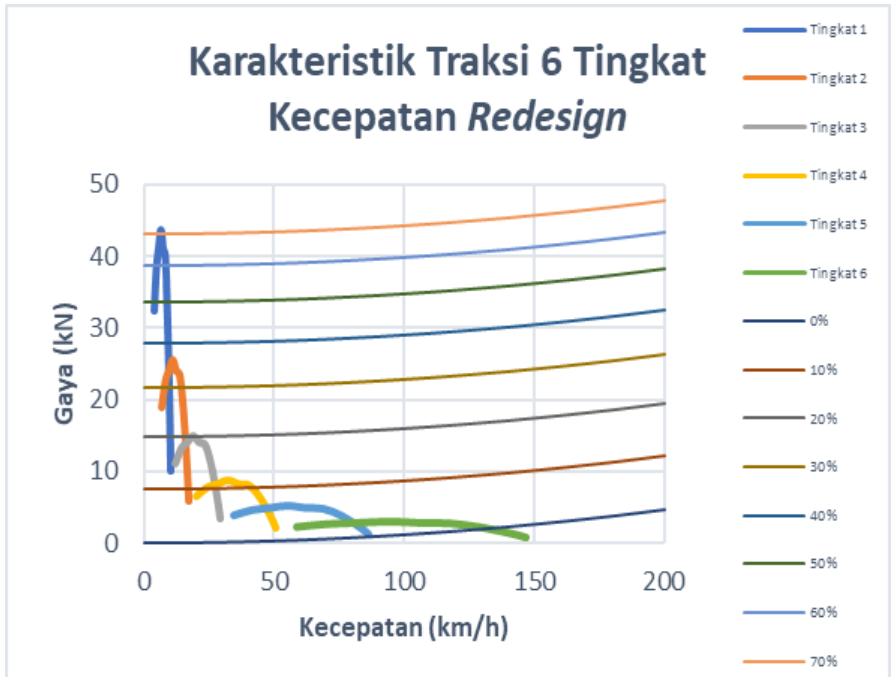

Gambar 6. Grafiik karakteristik traksi APC KOMODO 4X4 6 tingkat kecepatan hasil redesign.

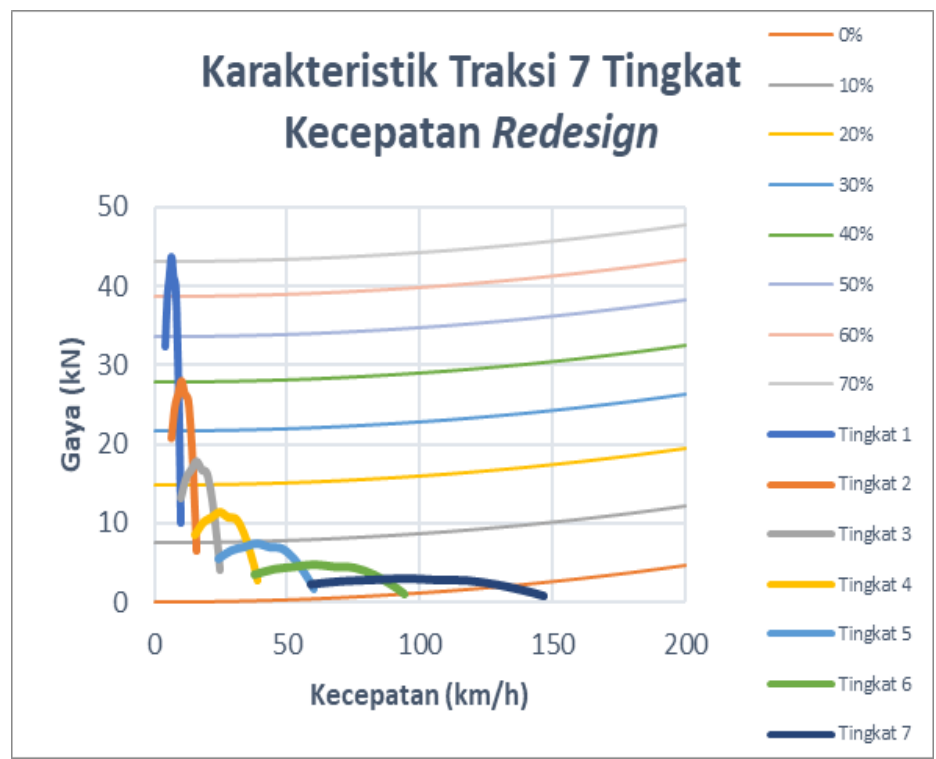

Gambar 7. Grafiik karakteristik traksi APC KOMODO 4X4 7 tingkat kecepatan hasil redesign. 


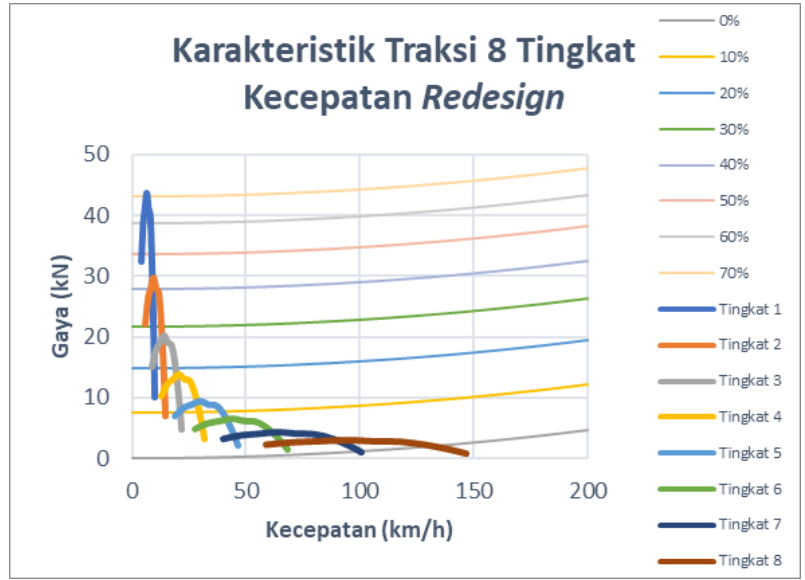

Gambar 8. Grafiik karakteristik traksi APC KOMODO 4X4 8 tingkat kecepatan hasil redesign.

Jika grafik karakteristik traksi kendaraan standar dibandingkan dengan grafik karakteristik traksi hasil redesign, dapat dilihat bahwa gradeability yang mampu dilalui kendaraan meningkat, begitu juga dengan kecepatan maksimumnya. Pada keadaan semula kendaraan hanya mampu melalui gradeability $50 \%$ dan kecepatan maksimum sebesar $110 \mathrm{~km} / \mathrm{jam}$. Setelah dilakukan redesign kendaraan mampu menempuh kecepatan $140 \mathrm{~km} / \mathrm{jam}$ dan gradeability $70 \%$.

Kemudian menggunakan metode pemeringkatan faktor, maka dapat ditentukan jumlah tingkat transmisi yang paling tepat berdasarkan penilaian bobot tertentu pada setiap faktornya. Faktor-faktor tersebut antara lain, efisiensi konstruksi (dimensi transmisi), distribusi traksi yang terjadi, percepatan, efisiensi transmisi, dan traksi yang dihasilkan pada setiap tingkat giginya.

Tabel 1.

Pemilihan jumlah tingkat transmisi berdasarkan bobot faktor tertentu

\begin{tabular}{|c|c|c|c|c|c|}
\hline & Bobot & Redesign 6 & Redesign 7 & Redesign 8 & \multirow{6}{*}{$\begin{array}{r}\text { Keterangan: } \\
1=\text { buruk } \\
2=\text { cukup } \\
3=\text { baik }\end{array}$} \\
\hline Efisiensi Konstruksi & 0.4 & 3 & 2 & 1 & \\
\hline Distribusi Traksi & 0.15 & 2 & 2 & 1 & \\
\hline Percepatan & 0.1 & 1 & 1 & 2 & \\
\hline Efisiensi Transmisi & 0.2 & 3 & 2 & 1 & \\
\hline Traksi Tiap Tingkat Gigi & 0.15 & 2 & 2 & 3 & \\
\hline & 1 & 2.5 & 1.9 & 1.4 & \\
\hline
\end{tabular}

Berdasarkan tabel diatas, dengan mempertimbangkan faktor-faktor yang telah disebutkan sebelumnya, dapat disimpulkan bahwa transmisi hasil redesign dengan 6 tingkat kecepatan memiliki poin yang paling besar. Sehingga hasil redesign transmisi yang digunakan adalah redesign dengan 6 tingkat kecepatan.

\section{KESIMPULAN/SARAN}

\section{A. Kesimpulan}

Berdasarkan data dan analisa yang telah dilakukan, diperoleh pada kondisi standar, kendaran APC KOMODO 4X4 mampu melaju dengan kecepatan maksimum sebesar 110 $\mathrm{km} / \mathrm{jam}$ pada tingkat gigi keenam. Sedangkan gradeability yang mampu dilalui adalah sebesar 50\%. Sehingga dapat dikatakan bahwa karakteristik traksi kendaran tidak sesuai dengan klaim pabrikan yang dicantumkan pada brosur kendaraan.

Setelah dilakukan redesign 6,7 , dan 8 tingkat transmisi, kendaraan mampu menempuh kecepatan maksimum sebesar $140 \mathrm{~km} / \mathrm{jam}$ dan gradeability $70 \%$. Kesimpulan yang dapat diperoleh dari hasil analisa adalah ketika rasio gear awal ditingkatkan maka gaya dorong yang dihasilkan oleh kendaraan juga meningkat, selain itu dengan menambah jumlah tingkat transmisi, losses yang terjadi pun semakin kecil. Tetapi, dengan meningkatkan rasio transmisi dan jumlah tingkat transmisi, perlu diperhatikan hal-hal lainnya, seperti dimensi gear, dimensi poros, dan dimensi transmission case.

Pada akhirnya, hasil redesign yang dianggap paling tepat adalah 6 tingkat dengan rasio tiap transmisinya 8.711; 5.095; $2.981 ; 1.743 ; 1.020 ; 0.6$.

\section{B. Saran}

1. Selain memvariasikan rasio pada setiap tingkat transmisi, rasio final drive atau gardan juga dapat divariasikan agar mampu mencapai perfoma kendaraan yang lebih optimal.

2. Perlu dilakukan analisa lebih lanjut mengenai desain detail susunan transmisi sebelum dan setelah dilakukan redesign agar dapat dipertimbangkan untuk produksi massal.

3. Perlu dilakukan analisa perhitungan menggunakan efisiensi aktual yang dapat ditentukan menggunakan pengujian dyno test pada kendaraan agar karakteristik traksi hasil perhitungan mendekati karakteristik traksi kendaraan pada kondisi aktual.

\section{DAFTAR PUSTAKA}

[1] J. J. Taborek, Mechanics of Vehicles. Ohio: Penton Publishing Co, 1957.

[2] dan B. S. Sutantra, I Nyoman, Teknologi Otomotif, Edisi Kedua. Surabaya: Guna Widya, 2010

[3] S. . Nyoman, Teknologi Otomotif Hybrid. Surabaya: Guna Widy a, 2015.

[4] P. Pindad, "Spesifikasi Komodo 4X4.," 2017. [Online]. Available: https://www.pindad.com/apc-4-x-4. 